\title{
Functional-Communicative Study of Adversative and Causal Discourse Markers
}

\author{
Siranush Khandanyan, Liza Mardoyan \\ Yerevan State University
}

W ithin the framework of the following article we will focus on the peculiarities of English adversative and causal discourse markers (DMs), mainly their functional and communicative study. The whole study would be incomplete if we did not take into consideration the role of discourse with its two forms - written and spoken. The whole discourse may be presented in the form of a specific building which is being constructed due to every new "brick" put on its foundations. Discourse markers are the "pillars" that help the "bricks" to construct the building.

Our main concern will be to define discourse, distinguish between its varieties and clarify the status of discourse markers in the study of discourse. The field of discourse is explored by the specifications of different types of discourse markers and by the revelation of their functional peculiarities in the organization of written text, their role in the achievement of coherent speech or speech patterns (monologue or dialogue) in written language. Since the study of discourse markers is rather new in linguistics their functional and communicative study is not devoid of difficulties and presents special consideration.

The diversity of the discourse field leads us to undertake a multidimensional linguistic inquiry of discourse study - textual discourse (determines how sentences/utterances are organized to form texts), pragmatic discourse (determines how sentences/utterances are related to the intentions of language users).

The whole nature of textual and pragmatic interpretation of DMs changes when we deal with dialogues and monologues in written discourse, which were taken as a main domain of our research on communicative function of adversative and causal DMs. In this case DMs have to carry out their role as text organizers and the elements introducing interactional features. It is due to this pragmatic and functional approach in the study of DMs that we witness their shift to multifunctionality (the ability to act as texture connector or pass to pragmatic use in written domain) (Ariel 1998:121).

Irrespective of the predominance of textual or pragmatic function, the common thing that all DMs share is connectivity. As opposed to other cohesive devices (conjunctions), discourse markers involve speaker choice. This is the reason why they are easily shifted from semantic domain into pragmatic one to fulfill the communicative function of the situational context. Thus, our main investigational routine is greatly connected with the investigation of the shift from semantic (textual) to pragmatic domain.

Irrespective of the main theories dealing with the study of discourse markers they abridge in the sense that they perceive similarly the main functions carried out by discourse markers - they act as contextual coordinates, they index adjacent utterances to the speaker/hearer or both, and they index the utterance to prior or subsequent discourse (Schiffrin 1995:52).

Within the boundaries of this article we will try to focus on those DMs which are very essential for the interpretation of discourse. It is the adversative and causal DMs that are 
endued with the ability of linking the sentence elements both formally and mentally, since adversative DMs indicate a contrary result or opinion to the content mentioned above. On the other hand, the importance of causal DMs in text organization is due to the need of justifications, reasoning, explanations and the addition of a new statement. As we are concerned with the clear-cut scrutiny of adversative DMs, we find it necessary to present a range of adversative DMs, illustrated by Fraser: but, alternatively, although, contrariwise, contrary to expectations, conversely, despite (doing) this/that, however, even so, in contrast (with/to this/that), in comparison (with/to this/that), on the contrary, nevertheless, nonetheless, regardless, still, as a matter of fact, at any rate, instead, yet, contrary to this (that), on the other hand, rather (than (do) this/that, still whereas, etc. (Fraser 1999:145). However, for the complete revelation of the peculiarities of adversative markers included in this range, we will speak about the notion of adversity and contrast. According to Schwenter contrast can be manifested indirectly but adversity provides explicit marking of clashes between different viewpoints with the help of discourse markers bearing the meaning of adversity (Schwenter 1999:126).

\author{
The Academy had an unquestionable beauty and its library was rather \\ modest. \\ (Th. More "Utopia" 2000:97) \\ The Coles were very good sort of people - friendly, liberal and unpre- \\ tending; but, on the other hand, they were of low origin, in trade, and only \\ moderately genteel. \\ (J. Austen "Emma” 1997:34)
}

The first example does not signal an explicit contrast, but hearers familiar with the link between the "richness" and "poverty" will perceive it nevertheless. But the adversative DM on the other hand in the second sentence, helps to determine an explicit difference between two parts of the sentence. In this sense the adversative markers indicate the beginning of a different viewpoint.

In order to understand the communicative nature of adversative discourse markers it becomes necessary and essential to examine the number of ways that conceptualize the interplay between viewpoints in language use and language structure. Roulet distinguishes between "monologues (one physical speaker) and dialogues (two-physical speaker), as well as between monological (one viewpoint) and dialogical (two viewpoints) discourses." (Roulet 1984:32).

The main distinction between monological and dialogical viewpoints is closely tied to whether the viewpoints are constructed as argumentatively parallel, i.e. oriented towards the same conclusion, or as argumentatively opposing, i.e. oriented toward different conclusions. To illustrate what is meant here, we will consider the following sentence.

$$
\begin{aligned}
& \text { Their separation did not exist in all its finality, but Jennie felt destruc- } \\
& \text { ted. } \\
& \text { (Th. Dreiser "Jennie Gerhardt" 1911:305) }
\end{aligned}
$$

Here, it is possible to isolate both the stated viewpoint that "Jane's feeling of destruction" was the cause of "their separation", and the underlying expectation that "their sepa- 
ration" will cause her "feeling of destruction". Thus, in this case, a single speaker is simultaneously advancing two viewpoints, which are in some sense incompatible, since the first part of the utterance (S1) presupposes a positive coloring of the second part of the utterance (S2). This presupposition is due to the negative use of the verb exist (did not exist) after a word separation (having negative connotation), which leads to a positive coloring of S2. The communicative features of DMs are revealed with more difficulty from monological (one-speaker) viewpoint, since we need to have a semantically and pragmatically burdened segment in the first part of the sentence, which helps the readers to deal with a more pragmatically burdened second part of the sentence.

Hereinafter, an example will be adduced, where we deal with a dialogue bearing monological viewpoint. It seems that $\mathrm{S} 2$ is the continuation of the thought expressed by the speaker of S1. Therefore, we deal with monological viewpoint in a dialogue.

Many a time has she said so; and yet I am no advocate for entire seclusion.

On the contrary, when people shut themselves up entirely from society, it is a very bad thing. $\quad$ (Th. Dreiser "Jennie Gerhardt" 1911:140)

In many cases one can witness a sentence presenting a dialogue which bears a dialogical viewpoint. The background for such a use is the unexpected thought expressed by the speaker of the second clause. This unexpected shift creates different lines of thoughts expressed by different speakers.

He would make her an ideal husband, his father would be pleased, everybody would be delighted.

Instead, he had drifted and drifted, and then he had met Jennie, and somehow; after that, he did not want her any more.

(Th. Dreiser "Jennie Gerhardt” 1911:310)

Within the limits of our interest was the revelation of the main communicative and functional features of adversative DMs with the help of their semantic shades unfolded due to the contextual interpretation. The main way of investigation carried for adversative DMs will be implemented in the process of exploring the communicative and functional peculiarities of causal DMs.

The importance of causal DMs is greatly connected with the role of causality. The latter is an important phenomenon in discourse, since it plays a crucial role in discourse understanding and question answering process. Second, causality is described as a major device for creating relevance in discourse becoming one among several principles of text organization.

It goes without saying that the investigation of causal DMs could be carried out after giving their general outline: because, for, on condition that, so that, supposing, although, even though, so, unless, hence, since, as a consequence, consequently, then, therefore, thus, as a result, accordingly, of course, on that condition, while, etc. In order to understand the communicative and functional nature of causal discourse markers, it becomes essential to pay attention to the intertwinement between the content, epistemic and speech 
act level. They together constitute the shift that one needs to pass from textual to the pragmatic fulfillment of causal DMs. The content and epistemic level are more similar to the monological viewpoint expressed by the adversative DMs. The content level is more similar to the monological viewpoint with semantic textual function, where the real-world causality between events is expressed. However, the epistemic level is more similar to the monological viewpoint with both pragmatic and textual functions, where the speaker's reasoning comes forth in statement comprehension process. The speech act level is the complete functional "twin" of dialogical viewpoint expressed by adversative DMs.

Ladies know what to fend hands against, because they read novels that tell them of these tricks.

(Th. Hardy "Tess of the d'Urbervilles" 2005:148) (content or fact level) John loved and appreciated her because he came back leaving the chain of all their grief behind.

(Th. Hardy "Tess of the d'Urbervilles" 2005:158) (epistemic level)

"Does Jack Dollop work here? - because I want him! I have a big bone to pick with him, I can assure you."

(Th. Hardy "Tess of the d'Urbervilles" 2005:158) (speech act level)

Thus, if we draw parallels between the functional and communicative nature of adversative and causal DMs, we see that they are rather similar in their realizations, in the sense that they carry out the textual function of elaboration and argumentation. The communicative function of adversative DMs is realized by the distinction between monological and dialogical viewpoints. However, in case of causal DMs the communicative function is mainly expressed on a speech act and epistemic level. Since a content causal sentence directly reflects a state of affairs in the world, it may be easier to process than an epistemic causal sentence, which does not directly express real-world causality. Therefore, the epistemic relation in some way is based on the underlying content relation (background knowledge) (Blakemore 1998:125).

In this model it becomes clear that some part of background knowledge is essential for the realization of the epistemic interpretation of the causal clause. Thus, in many cases the content level or non-content realization of a given discourse marker depends on its inner semantic background (whether it is more inclined to the fulfillment of communicative or textual function) as well as clausal environment.

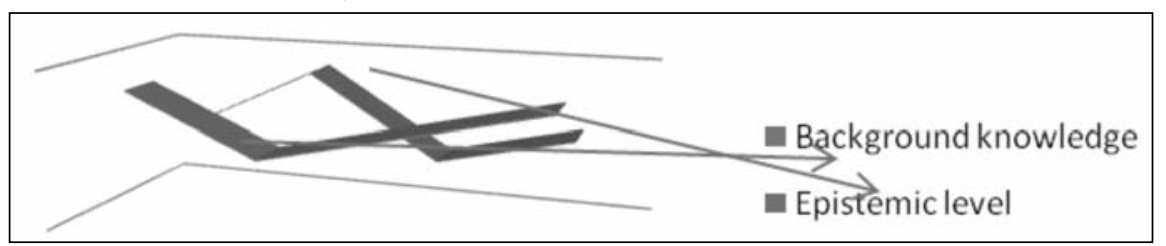

Any scientific research becomes more and more essential if it brings forth certain shreds of further investigation. We found it necessary to present in general outlines one of the important findings of our research - the overlap of causal and adversative DMs. 
The overlap was mainly possible in case we had the embedded core meaning of a given causal or adversative discourse marker. Due to that relation and clausal environment one could witness some shades of correlation between the discourse markers within the limits of our investigation. However, one of the crucial points of our findings was the fact that only a narrow range of discourse markers (adversative and causal) could be resorted to the overlap. Hereinafter we will present that set of DMs, that are exposed to this overlap (Blakemore 1998:125).

though, even, despite, although, however, still, while, thus

The probabilities were that he would be very fair and liberal. At the same time Robert was constantly beating her. Still, there was no certainty that the old gentlemen might do anything or nothing.

(Th. Dreiser "Jennie Gerhardt” 1911:146)

The interpretation of this example seems rather incomprehensible at first sight, and only the temporal meaning of the adversative marker still helps to unfold its extra semantic realizations in a given discourse. Not to mention the role of context, that becomes crucial for the adequate interpretation of the overlap of the marker still with causal meaning. Hereinafter, we find it necessary to resort ourselves to the representation of the main conclusions and findings drawn within the boundaries of this article.

The revelation of the communicative and functional peculiarities of adversative and causal DMs was crucial due to their argumentative and elaborative specifications in discourse structure. The upbringing process of these peculiarities was due to the unquestionable role of context as well as the cohesion and coherence. One could find the communicative and functional realizations of adversative DMs only with the help of dialogical and monological viewpoints. The study the textual and pragmatic function of causal DMs was due to the peculiarities of content, epistemic and speech-act levels.

The communicative function of adversative and causal DMs is more likely to occur when they are not too dependent on a given context. The presence of a "wide" context, which in itself has shades of low speech-act, hinders the total fulfillment of the communicative function, being more inclined to the textual one. These findings were useful for drawing the final framework of the communicative and functional study of adversative and causal DMs.

\section{References:}

1. Ariel, M. (1998) Pragmatic Operators. Oxford: Pergamon Press.

2. Blakemore, L. (1998) Semantic Constraints on Relevance. Oxford: Blackwell Inc.

3. Blakemore, L. (2001) Understanding Utterances. Oxford: Blackwell Inc.

4. Croucher, S. (2004) A Study of Discourse Marker Frequency in Impromptu Speaking. Oklahoma: Oklahoma University Press.

5. Dowing, A. (2006) English University Grammar. New York: Oxon Inc. 
6. Fraser, B. (1997) Contrastive Discourse Markers in English. Amsterdam: Benjamin Inc.

7. Fraser, B. (1999) An Approach to Discourse Markers. New York: Dobson Publishing House.

8. Fraser, B. (2009) Pragmatic Markers. New York: Dobson Publishing House.

9. Roulet, E. (1984) Speech Acts, Discourse Structure and Pragmatic Connectives. // International Journal of Pragmatics, 8. New York.

10. Schiffrin, D. (1987) Discourse Markers. Cambridge: CUP.

11. Schiffrin, D. (1995) Discourse Markers, Meaning and Context. Oxford: Maldon Press.

12. Schwenter, A. (1999) Viewpoints and Polysemy: Linking Adversative and Causal Meanings of Discourse Markers. Berlin: Berding Press.

\section{Sources of Data:}

1. Austen, J. (1997) Emma. London: Random House Group.

2. Dreiser, Th. (1911) Jennie Gerhardt. London: Random House Group.

3. Hardy, Th. (2005) Tess of the d'Urbervilles. New York: Random House Inc.

4. More, Th. (2000) Utopia. London: Random House Group.

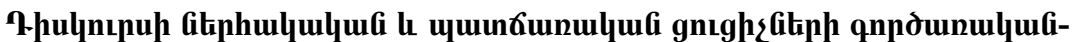

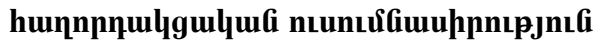

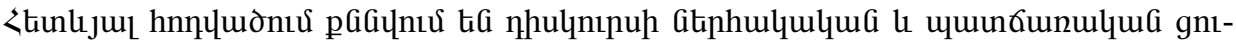

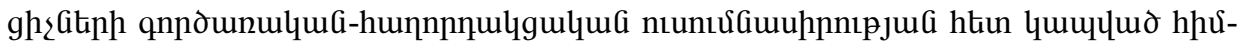

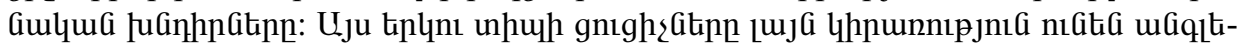

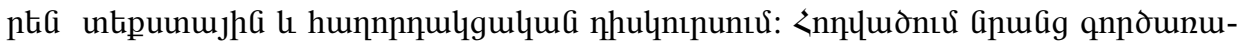

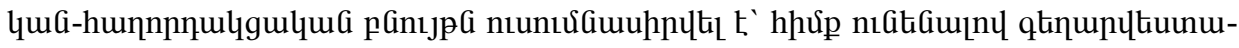

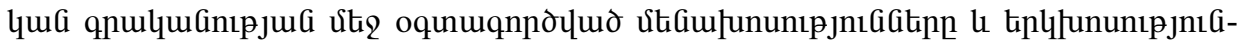

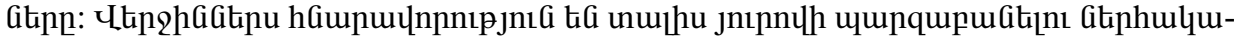

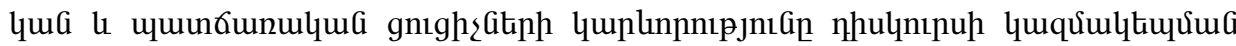

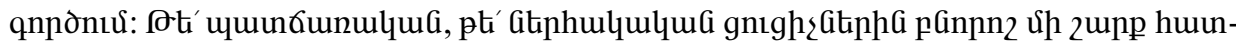

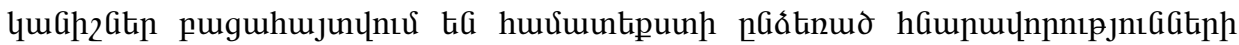

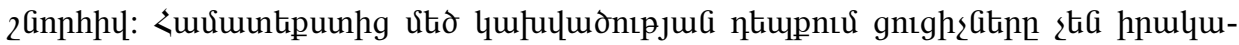

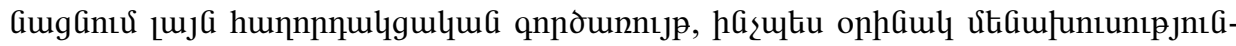

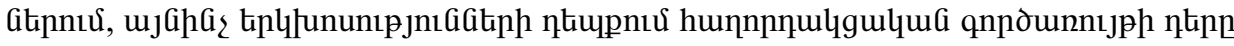
üəuGintu $\mathrm{t}$ : 